\title{
Surgical Treatment for Neonatal Hydrocephalus: Catheter-Based Cerebrospinal Fluid Diversion or Endoscopic Intervention?
}

\author{
Matthias Krause $^{1}$, Christos P. Panteliadis ${ }^{2}$, Christian Hagel ${ }^{3}$, Franz W. Hirsch ${ }^{4}$, Ulrich H. Thome ${ }^{5}$, \\ Jürgen Meixensberger ${ }^{1}$, Ulf Nestler ${ }^{*}$ \\ ${ }^{1}$ Department of Neurosurgery, University Hospital Leipzig, Leipzig, Germany \\ ${ }^{2}$ Department of Neuropediatrics and Developmental Neurology, University of Thessaloniki, Thessaloniki, Greece \\ ${ }^{3}$ Institute of Neuropathology, University Medical Center Hamburg-Eppendorf, Hamburg, Germany \\ ${ }^{4}$ Department of Pediatric Radiology, University Hospital Leipzig, Leipzig, Germany \\ ${ }^{5}$ Department of Neonatology, University Hospital Leipzig, Leipzig, Germany \\ Email: *ulf.nestler@medizin.uni-leipzig.de
}

How to cite this paper: Krause, M., Panteliadis, C.P., Hagel, C., Hirsch, F.W., Thome, U.H., Meixensberger, J. and Nestler, U. (2018) Surgical Treatment for Neonatal Hydrocephalus: Catheter-Based Cerebrospinal Fluid Diversion or Endoscopic Intervention? Open Journal of Modern Neurosurgery, 8, 30-45. https://doi.org/10.4236/ojmn.2018.81002

Received: October 10, 2017

Accepted: December 9, 2017

Published: December 12, 2017

Copyright (c) 2018 by authors and Scientific Research Publishing Inc. This work is licensed under the Creative Commons Attribution International License (CC BY 4.0).

http://creativecommons.org/licenses/by/4.0/

\begin{abstract}
Neonatal hydrocephalus can arise from a multitude of disturbances, among them congenital aqueductal stenosis, myelomeningocele or posthemorrhagic complications in preterm infants. Diagnostic work-up comprises transfontanellar ultrasonography, T2 weighted MRI and clinical assessment for rare inherited syndromes. Classification of hydrocephalus and treatment guidelines is based on detailed consensus statements. The recent evidence favors catheter-based cerebrospinal fluid diversion in children below 6 months, but emerging techniques such as neuroendoscopic lavage carry the potential to lower shunt insertion rates. More long-term study results will be needed to allow for individualized, multidisciplinary decision making. This article gives an overview regarding contemporary pathophysiological concepts, the latest consensus statements and most recent technical developments.
\end{abstract}

\section{Keywords}

Cerebrospinal Fluid, Hydrocephalus, Neonate, Neuroendoscopy, VP-Shunt

\section{The Cerebrospinal Fluid System}

The cerebrospinal fluid (CSF) system provides mechanical protection of the brain against mild trauma, is involved in nutrient supply and waste removal, and plays a role in the circadian rhythm [1]. In humans it comprises 4 cavities in the brain, the ventricles, which normally take up about $20 \%$ of the CSF. In addition, 
the cisternal and subarachnoid spaces contain $50 \%-60 \%$ of the CSF and the spinal compartment makes up for $20 \%-30 \%$ of the volume [2]. CSF is produced at an estimated rate of $0.3-0.4 \mathrm{ml} / \mathrm{min}$ in the choroid plexus of all four ventricles, the brain interstitium and in leptomeningeal surfaces. It circulates from the ventricles to the subarachnoid space, where it is reabsorbed into the venous system via arachnoid granulations and paravascular pathways or drained into the lymphatics, e.g. the nasal submucosa [3] [4]. The term "glymphatics" describes the heart-beat driven, pulsatile flow of CSF and interstitial fluid from the glial compartment to the recently reported lymphatic dural vessels [5].

\section{Hydrocephalus}

Hydrocephalus is a disbalance between CSF production and resorption. In most cases, the increased amount of cerebrospinal fluid results in an enlargement of the inner CSF spaces. Hydrocephalus does not represent a disease in itself, but constitutes a symptom of various underlying conditions, such as obstruction of CSF flow ("occlusive hydrocephalus") or dysfunction of CSF reabsorbing surfaces ("malresorptive hydrocephalus"), with certain forms of hydrocephalus occurring predominantly in distinct age groups [6].

Especially neonatal hydrocephalus is a well-known condition with an incidence of 0.2 to $3.5 / 1000$ healthy births. Up to $40 \%$ of cases are diagnosed during the first 6 months of life [7]. For some of the pediatric hydrocephalic conditions, the "classic" pathophysiologic concepts are still valid, such as the acute occlusive, "non-communicating" form with obstruction of the Sylvian aqueduct. In other conditions, e.g. multicystic compartments, syringomyelia or chronic communicating forms, further considerations of brain water circulation and CSF pulsatile flow gradients are needed for conclusive pathophysiological explanations, resulting in contemporary classifications (Table 1) [8] [9].

\section{Clinical Presentation}

Most children with hydrocephalus suffer from a chronic disease with a rather slow progress of symptoms. Only $10 \%-15 \%$ of newborns with hydrocephalus show signs of elevated intracranial pressure [11].

In preterm infants, hydrocephalic growth of the neurocranium is preceded by an ultrasonographically detectable enlargement of the ventricles. At this time, the endochondral bone formation of the skull fragments still allows for a certain flexibility and the small children often suffer from a multitude of additional regulatory deficits owing to their immaturity. Therefore the signs of increased intracranial pressure such as bradycardia or respiratory insufficiency are less obvious than in older children. In newborns or infants under the age of 2, the crossing of percentiles of the head circumference compared to body height and weight is the most important sign of isolated hydrocephalus [11].

Typical concurring symptoms are a tight, bulging anterior fontanel, dehiscence of skull sutures, increased visibility of scalp veins and a huge frontal bone 
Table 1. Consensus according to the "point of obstruction" model by the hydrocephalus classification study group 2010, modified from [10].

\begin{tabular}{|c|c|c|}
\hline Point of obstruction & $\underline{\text { Differential diagnosis }}$ & Treatments available \\
\hline Foramen of Monro & $\begin{array}{l}\text { Tumor } \\
\text { Congenital absence } \\
\text { Ventriculitis } \\
\text { Functional }\end{array}$ & $\begin{array}{l}\text { Shunt (unilateral or bilateral) } \\
\text { Endoscopic septum opening }\end{array}$ \\
\hline Aqueduct of Sylvius & $\begin{array}{l}\text { Tumor } \\
\text { Birth defect } \\
\text { Secondary }\end{array}$ & $\begin{array}{l}\text { Shunt } \\
\text { Endoscopic third ventriculostomy }\end{array}$ \\
\hline 4th Ventricle foramina & $\begin{array}{l}\text { Infection } \\
\text { Tumor } \\
\text { Severe Chiari Malformation }\end{array}$ & $\begin{array}{l}\text { Shunt } \\
\text { Endoscopic third ventriculostomy } \\
\text { Surgical opening }\end{array}$ \\
\hline $\begin{array}{l}\text { Spinal to cortical } \\
\text { subarachnoid space }\end{array}$ & $\begin{array}{l}\text { Subarachnoid hemorrhage } \\
\text { Infection }\end{array}$ & $\begin{array}{l}\text { Shunt (ventriculo- or lumboperitoneal) } \\
\text { Endoscopic third ventriculostomy }\end{array}$ \\
\hline Arachnoid villi & $\begin{array}{l}\text { Hemorrhage } \\
\text { Infection }\end{array}$ & $\begin{array}{l}\text { Shunt (ventriculo- or lumboperitoneal) } \\
\text { Neuroendoscopic lavage }\end{array}$ \\
\hline Venous hypertension & $\begin{array}{l}\text { Pseudotumor } \\
\text { Congenital hydrocephalus } \\
\text { Sinus thrombosis }\end{array}$ & $\begin{array}{l}\text { Shunt (ventriculo- or lumboperitoneal) } \\
\text { Clot lysis } \\
\text { Bariatric surgery for obesity-related } \\
\text { pseudotumor }\end{array}$ \\
\hline
\end{tabular}

italic: additions/changes to original publication [10].

(frontal bossing). Retraction of the upper eye-lids, together with Parinaud's upgaze palsy can lead to the rare, but very impressive sunset phenomenon, with both irises plunging half below the lower eye-lids.

A number of hereditary syndromes, which mostly follow a recessive inheritance, are associated with hydrocephalus (Table 2). Thus, pediatric patients suffering from hydrocephalus of unknown etiology should be examined thoroughly for stigmata indicating an inherited disease.

In older children acute symptoms are bifrontal or bioccipital headache, nausea and vomiting, followed by somnolence, irritability, bradycardia and lastly bradypnea. Chronic symptoms comprise changes in personality, memory disturbances and a cognitive decline, sometimes up to the full Hakim triad of normal pressure hydrocephalus with a demential syndrome, gait ataxia and urinary incontinence.

The development of papilledema ("choked disc") with subsequent risk of optic atrophy requires at least 48 to 72 hours of increased intracranial pressure. It has to be monitored in the follow-up of chronic hydrocephalic conditions. However, it offers only a very low sensitivity to rule out hydrocephalus or increased ICP, and it is seldom seen in children under the age of 12 months [11].

\section{Imaging}

During the fetal period, hydrocephalic conditions can be diagnosed ultrasonographically after 16 to 18 weeks of gestation. Due to the small structures and to 
Table 2. Inherited syndromes associated with hydrocephalus, adopted from [12].

\begin{tabular}{|c|c|c|}
\hline Syndrome & Symptoms & Inheritance \\
\hline $\begin{array}{l}\text { Bickers-Adams } \\
\text { (x-linked } \\
\text { hydrocephalus HSAS) }\end{array}$ & $\begin{array}{l}\text { aqueductal stenosis } \\
\text { adduction deformities of the thumbs } \\
\text { L1CAM gene mutation }\end{array}$ & $\mathrm{x}$ chromosmal recessive \\
\hline $\begin{array}{l}\text { Hydrocephalus withou } \\
\text { aqueductal stenosis }\end{array}$ & mental retardation & $\mathrm{x}$ chromosomal recessive \\
\hline Hydrolethalus & $\begin{array}{l}\text { microphthalmia } \\
\text { polydactyly } \\
\text { congenital heart disease } \\
\text { pulmonal hypoplasia }\end{array}$ & autosomal recessive \\
\hline Meckel & $\begin{array}{l}\text { polycystic kidneys } \\
\text { polydactyly } \\
\text { encephalocele }\end{array}$ & $\begin{array}{l}\text { autosomal recessive MKS1: chr } 17 \\
\text { MKS2: chr } 11 \\
\text { MKS3: chr } 8\end{array}$ \\
\hline VACTERL association & $\begin{array}{l}\text { vertebral anomalies of the spine } \\
\text { anal atresia } \\
\text { congenital heart disease } \\
\text { tracheo-esophageal fistula } \\
\text { renal abnormalities } \\
\text { limb malformations }\end{array}$ & $\begin{array}{l}\text { when associated with } \\
\text { hydrocephalus: autosomal } \\
\text { recessive or } x \text {-linked }\end{array}$ \\
\hline VATER association & $\begin{array}{l}\text { macrocephaly } \\
\text { ventriculomegaly }\end{array}$ & autosomal recessive \\
\hline Waaler-Aarskog & $\begin{array}{l}\text { Sprengel anomaly (undescended scapula) } \\
\text { costovertebral dysplasia }\end{array}$ & probably autosomal dominant \\
\hline $\begin{array}{l}\text { Walker-Warburg } \\
\text { (Cerebro-Oculo-Muscu } \\
\text { lar Syndrome COMS) }\end{array}$ & $\begin{array}{l}\text { lissencephaly } \\
\text { retinal dysplasia and anomalies of the } \\
\text { anterior ocular chamber } \\
\text { severe neurological dysfunction } \\
\text { encephalocele }\end{array}$ & autosomal recessive: $\mathrm{chr} 9 \mathrm{q} 34.1$ \\
\hline
\end{tabular}

child movements, fetal MRI remains difficult to interprete before the $24^{\text {th }}$ week [13]. A recent study demonstrated the diagnostic accuracy of prenatal ultrasound to be around $70 \%$ and to be increased to more than $90 \%$ by additional intrauterine MRI, already at 18 weeks of gestation. Since in one third of study patients the clinical management was changed after obtaining the MRI results, intrauterine MRI is recommended as soon as possible after ultrasonographic suspicion of fetal brain anomaly [14].

In newborns, transfontanellar ultrasound can be considered as the standard diagnostic tool, offering ease of use, bed-side availability and close serial followup surveillance of therapy [15]. Detailed neuroradiologic examination of hydrocephalus is done by T2-weighted images in three planes in order to assess ventricle size (axial), patency of the aqueductus mesencephali (sagittal, flow void) and size of the interventricular foramina (coronary) for potential neurosurgical endoscopic access. Flow-suppressed CISS sequencing allows for visualisation of anatomic structures, points of obstruction and multiple intraventricular compartments. If infection or tumor are suspected, contrast enhanced pictures are 
needed.

MRI data can be used for neuronavigation-guidance of the endoscope and should be performed before a first CSF diversion procedure, in atypical cases or when obstructive pathologies are suspected.

\section{Therapy-Principles}

As derived from the "point of obstruction" model, hydrocephalus is a mismatch between CSF production, outflow and resorption (Table 1). Thus, the therapeutic principle is to restore CSF outflow dynamics and to reestablish physiological pulsatile forces [16]. This can either be achieved by neurosurgical removal of the occluding structure (e.g. cerebellar tumor), by endoscopic opening of an alternative CSF egress route to the outer subarachnoid resorbing surfaces and glymphatic pathways, or by placing a shunt to deviate CSF towards alternative resorbing compartments e.g. the peritoneum.

\subsection{Acute Hydrocephalus}

An acute symptomatic hydrocephalus without a clear point of obstruction requires immediate treatment by placement of an external ventricular drainage. In preterm and newborn infants before complete ossification of the bony skull, a percutaneous puncture through the anterior fontanel, lateral to the midline, can be the first emergency measure. Repeated ventricular tapping should be avoided because of the increased risk for infection or periventricular defects, especially in premature children. In these patients, implantation of a ventricular access device (VAD, e.g. Rickham reservoir) is recommended. The intervention and the final intraventricular position of the drainage or device are to be controlled ultrasonographically. In older children, a burr hole trepanation is needed. In doubtful cases, an external drainage or a Rickham reservoir can also be left in place after endoscopic third ventriculostomy (ETV) until final resolution of the hydrocephalic condition.

\subsection{Endoscopic Treatment}

Endoscopic fenestration is typically indicated in triventricular hydrocephalus, when obstruction of the Sylvian aqueduct leads to a non-communicating situation. Furthermore, outflow obstructions at the 4th ventricle foramina and above the level of the foramen magnum have a high success rate for endoscopic approaches [17]. In the three ventricles proximal of the mesencephalic stenosis the reduced CSF outflow results in increased ventricular volume. Endoscopic third ventriculostomy (ETV) is the fenestration of the caudal membrane of the third ventricle between pituitary recess and mamillary bodies. It opens an alternative drainage route out of the cerebral ventricular system, rostral to the basilar artery and to the brainstem. ETV allows CSF outflow down to spinal subarachnoid resorption areas and lymphatic drainage routes (Figure 1). Additional endoscopic cauterization of choroid plexus with the aim to reduce CSF production has been 


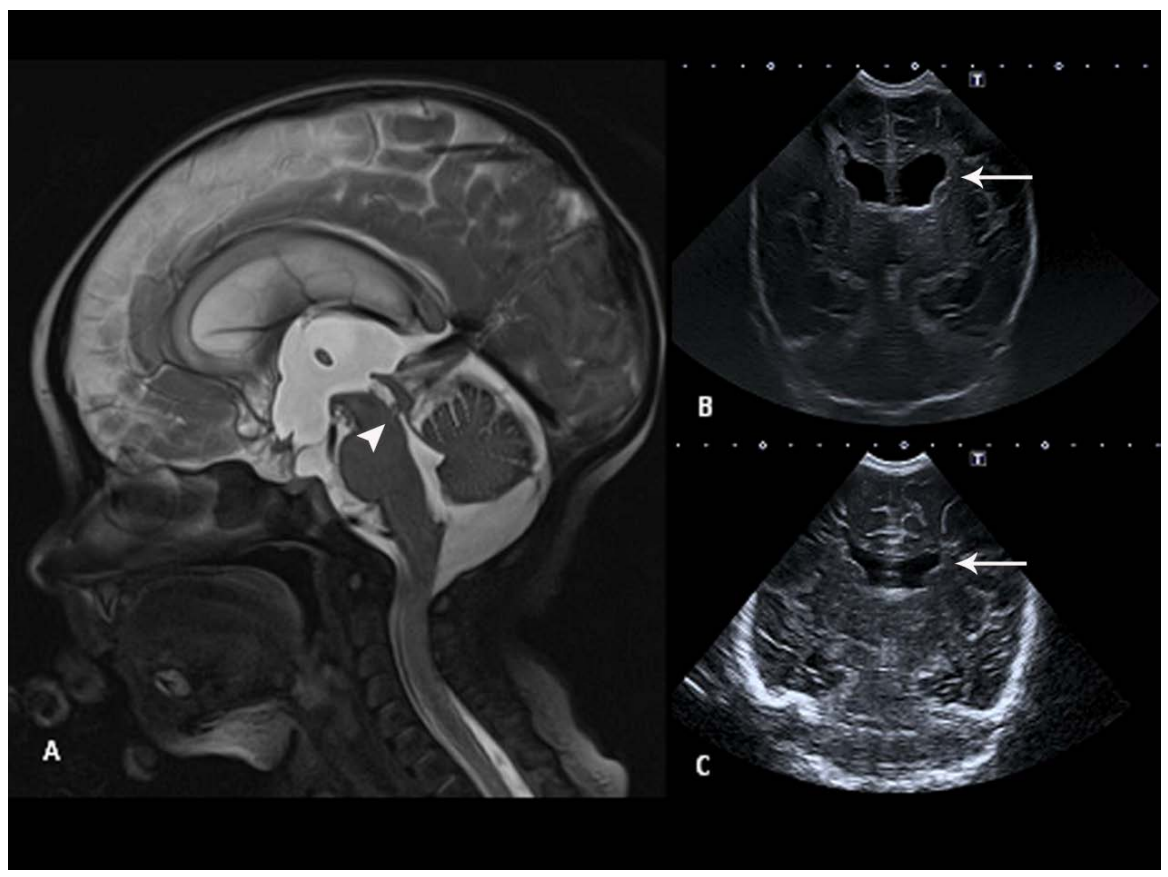

Figure 1. Neonate boy, cesarean section in the $40^{\text {th }}$ gestational week after prenatal ultrasonography had demonstrated an intraventricular hemorrhage and increasing ventricular sizes. On day 8 after birth ETV was performed A: Sagittal T2 MRI 6 days after birth, showing aqueductal stenosis (arrowhead); B: Coronary transfontanellar ultrasonography on the first postoperative day (day 9) showing hydrocephalic configuration of the ventricles (arrow) and the endoscopic trajectory at the right ventricle roof; C: Transfontanellar ultrasonography two months after surgery demonstrating diminished hydrocephalus (arrow, original imaging by FWH and UHT).

attempted, only with moderate success [18].

For multicystic hydrocephalus, additional endoscopic fenestration of the noncommunicating cysts can be necessary, often in repeated neurosurgical sessions. In most cases, a VAD reservoir is left in place for frequent withdrawal of CSF, or a combined approach using ventriculo-peritoneal shunting and endoscopic fenestration is chosen [19].

\subsection{Shunt Treatment}

Ventriculo-peritoneal shunt placement can be considered as the standard surgical treatment since the Assisi consensus conference in 1992 and most centres report to place VP-shunts much more often than ventriculo-atrial shunts [20]. In VP-shunts, placement of the distal catheter is less complicated, fewer revision surgeries are needed for catheter prolongation and eventual distal tip complications provoke less severe sequelae. It has been found, that implantation of shunt systems with a programmable valve helps in avoiding complications such as overdrainage or underdrainage and especially lowers the rate of revision surgeries [21]. In all types of shunt CSF diversion, a close, life-long follow-up of the patients is mandatory, with regular examinations concerning neurologic development, cognitive abilities and visual acuity, in order to detect imminent shunt- 
malfunction [22] [23].

\subsection{Shunt Infections}

Most shunt infections occur within the first 12 months after implantation, predominant germs are Staphylococcus epidermidis (about 40\%) and Staphylococcus aureus (about 20\%). Analysis of CSF allows for microbiologic assessment and often reveals pleocytosis with moderately increased protein levels. In shunt infections with Propionibacteriaceae CSF analysis and clinical symptoms can remain non-diagnostic. These infections can lead to abdominal pseudocystic lesions and the microbiologic detection only becomes positive after two to three weeks of incubation. In difficult cases, the diagnostic assessment should be broadened to cover protozoae [24].

The risk of perioperative shunt infection ranges around 5\% and is higher in neonatal patients. It can be lowered by a preoperative single-shot antibiotic treatment, twenty minutes before skin incision, by 24 -hour prophylactic postoperative antibiotic treatment or by using an antibiotic-impregnated catheter system [25] [26] [27]. In case of a shunt-infection, the system is to be removed completely, and eventually a temporary external ventricular drain has to be inserted [28]. Re-insertion of the shunt should be postponed until three microbiologic CSF samples without bacterial growth after 48 hours of incubation have been obtained. In the meantime, oral or intravenous antibiotic treatment is administered according to the antibiogram, in complicated cases; vancomycin or gentamicin can be instilled intrathecally via the external drain.

\section{Therapy-Specific Neonatal Situations}

\subsection{Intraventricular Hemorrhage (IVH) in Premature Infants}

In $15 \%-20 \%$ of cases, hydrocephalus results from intraventricular hemorrhage [12]. In preterm infants with intraventricular hemorrhage, high CSF protein content and small body weight increase the risk of neurosurgical treatment. In correlation with the severity of germinal matrix hemorrhage, an increasing percentage of patients require a permanent CSF diversion (VP-shunt). Conservative options using acetazolamide $(100 \mathrm{mg} / \mathrm{kg} / \mathrm{d})$ or furosemide $(1 \mathrm{mg} / \mathrm{kg} / \mathrm{d})$, proved to be ineffective to relieve hydrocephalic CSF circulation disturbances or to reduce the number of shunt implantations needed [29].

Neither repeated lumbar or ventricular punctures, nor intrathecal fibrinolysis (e.g. with streptokinase or tissue plasminogen activator) have lowered shunt implantation rates or improved long-term neurological outcome [15]. To diminish the risk of an infection, subcutaneous implantation of puncture reservoirs (VAD, as Ommaya or Rickham reservoirs) is encouraged for repeated CSF tapping, the proximal catheter being positioned into one lateral ventricle [30]. A subcutaneously free ending ventriculo-subgaleal (VSG-) shunt can be placed to reduce the frequency of punctures [31]. If ventricular enlargement cannot be treated sufficiently in this way, a peritoneal shunt system will subsequently be 


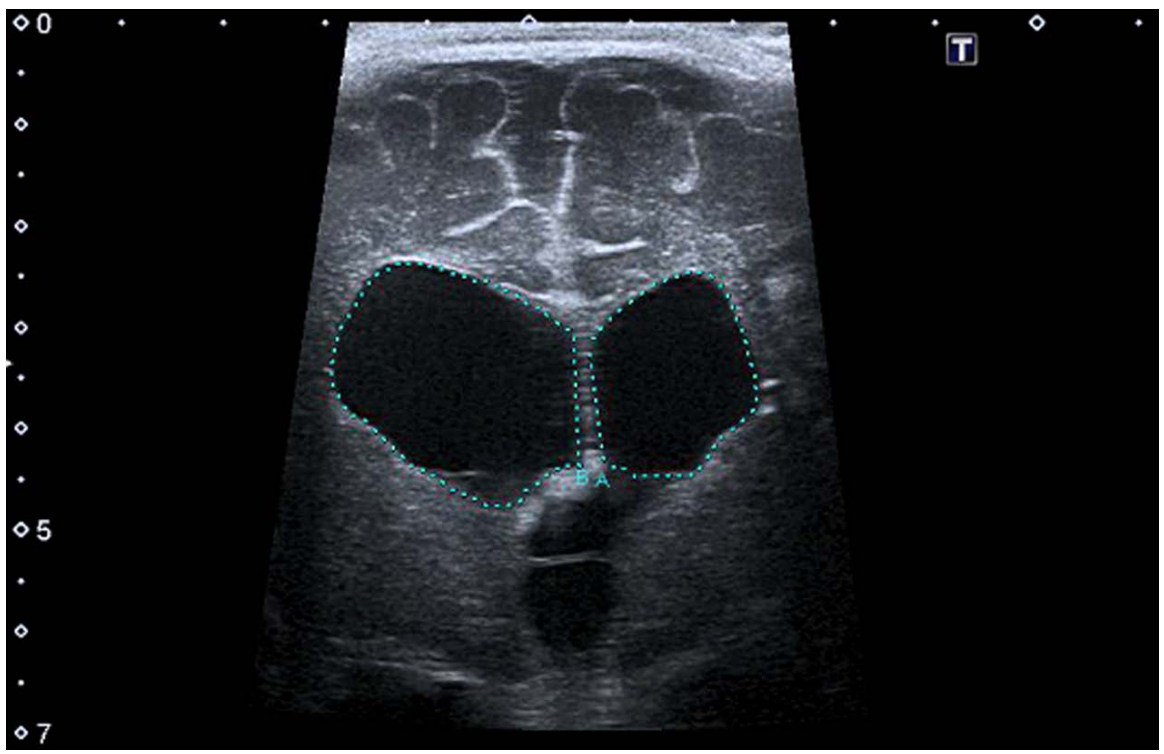

Figure 2. Preterm girl, birth at $25^{\text {th }}$ week of gestation, IVH II . Repeated transfontanellar ultrasonography revealed a clinically inapparent ventricular enlargement for the first time 4 months after birth. Assessment of ventricle areas in a coronary plane at the level of the foramen of Monro (normally below $2 \mathrm{~cm}^{2}$ ). A: left ventricle, area $2.47 \mathrm{~cm}^{2}$; B: right ventricle, area $4.20 \mathrm{~cm}^{2}$ (Original imaging by FWH and UHT).

connected to the subcutaneous catheter tip or the reservoir [15].

Recently, endoscopic lavage of the ventricular system has been proposed, in order to remove post-hemorrhagic residuals from the ependyme and to clear CSF content [32]. This should preferentially be performed at onset of posthemorrhagic hydrocephalic configuration, which often occurs between day 10 and 28 after birth. Ultrasonographic assessment of the ventricle area in a coronary view on the level of the foramen of Monro (normally below $2 \mathrm{~cm}^{2}$ ) has been shown to be most useful for early detection of increasing ventricle size (Figure 2).

During neuroendoscopic lavage, insertion of a straight endoscope into the supratentorial ventricular system is followed by irrigation to remove blood clots and posthemorrhagic sludge, as well as to restore physiological CSF circulation and outflow routes. Long-term results, comparing the potential neurological benefits with the higher surgical risks, are not yet available in premature neonates [32]. According to our own observations, the neonatal patients after neurosurgical endoscopic lavage require fewer interventions for CSF diversion.

\subsection{Multicompartment Hydrocephalus}

Especially after ventriculitis or meningitis a multicystic hydrocephalus can develop, containing highly fibrinogenic protein-rich CSF, which easily leads to catheter obstruction [33]. In these cases, endoscopic cyst fenestration, together with placement of a "stent-like" free catheter tip in between cysts, or insertion of cerebral catheters connected to a shunt system, can re-establish functional and pulsatile CSF flow through the labyrinth-like ventricular system [34]. Endoscop- 
ic lavage to dilute CSF protein content, similar to IVH patients, has been described for difficult cases, reportedly with encouraging results [35].

\subsection{Triventricular Hydrocephalus}

Aqueductal stenosis is a typical cause of triventricular hydrocephalus in neonates. When aqueductal stenosis is associated to L1CAM-mutations, $\mathrm{x}$-linked hydrocephalus or malformations such as holoprosencephaly, the patients have a high risk for impaired neurological development. Isolated AQS can remain clinically asymptomatic for years and the patients have a similar long-term outcome as healthy peers [22]. A consequent life-long follow-up of neurologic symptoms is mandatory, once the radiologic diagnosis has been made [33]. When symptoms occur, the treatment of choice is endoscopic third ventriculostomy (ETV).

\subsection{Tumors}

Congenital mesencephalic tumors or cerebellar tumors, such as pilocytic astrocytoma or medulloblastoma, can lead to hydrocephalus because of CSF outflow reduction from the posterior fossa. However, symptomatic congenital tumors within the posterior fossa are very rare, posterior fossa tumors generally develop later in life [36]. In order to restore CSF flow, the tumors have to be removed neurosurgically, as completely as possible. In certain cases, endoscopic third ventriculostomy can be indicated, if the prepontine subarachnoid space is not obtruded by the anterior brainstem shift induced through the space-occupying lesion. Otherwise, implantation of a shunt system is needed.

\subsection{Neural Tube Defects}

During fetal development, pulsatile CSF flow is involved in shaping the chondroid skull, especially the size of the posterior fossa. In neural tube defects, e.g. myelomeningocele, pulsatile and hydraulic forces are lost, because spinal CSF is draining into the amniotic cavity. This often leads to a small size of the posterior fossa, which in turn cannot accommodate the developing and growing cerebellar structures. This so-called Chiari-malformation then results in compression of the medulla oblongata by caudally displaced parts of the cerebellum, accompanied by respiratory problems of the newborn and by hydrocephalus, sometimes even syringomyelia.

Spinal myelomeningoceles are to be closed neurosurgically during the first 48 hours after birth, to avoid ascending infections and secondary mechanical damage to the medullary cord. The sudden stop of spinal CSF egress increases the production/resorption mismatch and eventually aggravates the symptoms of the Chiari malformation. Therefore, about $80 \%$ of children with perinatal myelomeningocele will need placement of a shunt system in the days following the first surgery [37] [38]. In severe cases, additional neurosurgical decompression of the posterior fossa and the dorsal arches of the upper cervical spine has to be considered. 
Recent studies have reported endoscopic third ventriculostomy to be a feasible and safe alternative to shunt placement in these patients, with comparable success rates [39] [40]. Antenatal open fetal surgery or fetoscopic repair of the neural tube defect has been shown to reduce the rate of shunt-dependent hydrocephalus below 50\% [41] [42]. However, long-term results are not yet available concerning neurologic and cognitive outcome with these treatments.

\section{Controversy}

Endoscopic fenestration versus shunt implantation.

Intraventricular endoscopic fenestration has been established as a standard neurosurgical intervention during the last 25 years. Compared to shunt placement, the most obvious advantage is prevention of foreign material implantation into the patient's body, avoiding the pitfalls of shunt obstruction or infection. Early studies showed the complication rates and the frequency of revisions to be lower and the long-term patency rates of CSF stomies to favor endoscopy [17] [43].

More recent publications indicated equipoise of both techniques [44] [45]. A multicenter retrospective analysis in more than 5000 infants found that repeated CSF diversion surgery was necessary in $64.5 \%$ of patients after ETV as first intervention, compared to $39.6 \%$ of infants with shunt placement [46]. In the International Infant Hydrocephalus Study (IIHS) for aqueductal stenosis, a prospective multicenter comparison of both techniques, treatment failure was defined as the need for neurosurgical re-operation to divert CSF, or death because of hydrocephalus. Using this definition, one-year-success rate for ETV was $66 \%$ compared to $83 \%$ for shunt placement. Especially children below 6 months of age seemed to fare worse with ETV [47]. The 5-year-follow-up data is in preparation.

In a retrospective analysis of own neonatal patients, neurologic outcome after ETV was worse compared to VP-shunt, only when ETV did not improve ventriculomegaly [6]. Persistent ventriculomegaly is not unequivocal for determining the success of hydrocephalus treatment, but it puts neonatal children at risk for impaired neurological development [48] [49]. In our view, endoscopic intervention offers an additional advantage to visualize and inspect parts of the CSF pathways, as well as to dilute and clean CSF contents. Close neurologic followup and ultrasonographic observation of ventricular size is required to decide whether and when shunt implantation is needed after ETV.

Especially in the neonatal setting, both techniques should be readily available and have to be regarded as complementary approaches, which can easily be combined. Individualized decision making in a multidisciplinary setting remains mandatory, probably even after arrival of the projected data analyses of the ongoing studies.

\section{Long-Term Results}

In general, hydrocephalic children suffer from an increased risk for developmental delay and an increased mortality. Besides the surgical letality (approx- 
imately $8 \%$ ), the mortality rate over 20 years of follow-up has been reduced from $39 \%$ in the 1960 s to $21 \%$ in the 1980 s for patients without a tumor as underlying disease [50] [51]. Many patients present with neurologic deficits such as motor, visual or auditory impairment, and a huge number of deaths is due to delayed diagnosis of CSF diversion malfunction, regardless whether a shunt implantation or an endoscopic fenestration have been performed [11] [43].

The neurologic and intellectual development depends largely on the etiology of the hydrocephalus and the intercurrent diseases such as intracranial hemorrhage, ventriculitis or accompanying epileptic seizures. For example, children with neural tube defects or aqueductal stenosis fare better than patients with concomitant epilepsy, which is present in up to $30 \%$ of patients [52]. Compared to the healthy population, children with hydrocephalus are challenged in view of motoric functions, nonverbal tasks and executive functions, but in $40 \%$ to $65 \%$ of treated patients normal intellectual capacities have been shown. The preschool level of verbal capacities allows estimating further development [23].

Visual disturbances require special attention, because in more than two thirds of the patients, accompanying ocular problems, such as strabism or refractory deficits, are present, and in $9 \%$ of grown-up patients visual loss is the only symptom of delayed shunt malfunction [11].

In neuroradiologic follow-up, the term "hydrocephalus e vacuo" is a highly controversial diagnosis. It describes a situation in which the loss of cerebral tissue leads to enlarged CSF-filled intracranial spaces, without increased intracranial pressure or CSF production/resorption mismatch. These e-vacuo situations can only be unequivocally diagnosed by invasive intracranial pressure monitoring and the onset of symptoms in chronic hydrocephalus can be delayed for decades [6]. This underlines the importance of close, life-long follow-up examinations, once a stable clinical and neurological situation has been achieved for the patients.

\section{Future Directions}

The development and refinement of endoscopes, for example the in-catheter endoscope, will allow for less invasive and more accurate positioning of shunt catheters, probably together with ventricular lavage, combining both techniques with neuronavigation. This may lead to decreased rates of shunt malfunction by diminishing the amount of debris, cellular structures and proteins in CSF before placement of catheters. However, meticulous long-term follow-up is needed to disclose the least harmful treatment strategy in the small and vulnerable patients.

\section{References}

[1] Tumani, H. (2015) Physiology and Constituents of CSF. In: Deisenhammer, F., Sellebjerg, F., Teunissen, C.E. and Tumani, H., Eds., Cerebrospinal Fluid in Clinical Neurology, Springer International Publishing, Switzerland. https://doi.org/10.1007/978-3-319-01225-4_3

[2] Hartman, A.L. (2009) Normal Anatomy of the Cerebrospinal Fluid Compartment. 
In: Irani, D.N., Ed., Cerebrospinal Fluid in Clinical Practice, Saunders/Elsevier, Philadelphia. https://doi.org/10.1016/B978-141602908-3.50005-4

[3] Hladky, S.B. and Barrand, M.A. (2014) Mechanisms of Fluid Movement into, through and out of the Brain. Evaluation of Evidence Fluids Barriers CNS, 11, 26. https://doi.org/10.1186/2045-8118-11-26

[4] Iliff, J.J., Wang, M., Zeppenfeld, D.M., Venkataraman, A., Plog, B.A., Liao, Y., Deane, R. and Nedergaard, M. (2013) Cerebral Arterial Pulsation Drives Paravascular CSF-Institial Fluid Exchange in the Murine Brain. Journal of Neuroscience, 33, 18190-18199. https://doi.org/10.1523/JNEUROSCI.1592-13.2013

[5] Louveau, A., Smirnov, I., Keyes, T.J., Eccles, J.D., Rouhani, S.J., Peske, J.D., Derecki, N.C., Castle, D., Mandell, J.W., Lee, K.S., Harris, T.H. and Kipnis, J. (2015) Structural and Functional Features of Central Nervous System Lymphatic Vessels. Nature, 16, 337-341. https://doi.org/10.1038/nature14432

[6] Rodis, I., Mahr, C.V., Fehrenbach, M.K., Meixensberger, J., Merkenschlager, A., Bernhard, M.K., Schob, S., Thome, U., Wachowiak, R., Hirsch, F.W., Nestler, U. and Preuss, M. (2016) Hydrocephalus in Aqueductal Stenosis-A Retrospective Outcome Analysis and Proposal of Subtype Classification. Child's Nervous System, 32, 617-627. https://doi.org/10.1007/s00381-016-3029-y

[7] Green, A.L., Pereira, E.A., Kelly, D., Richards, P.G. and Pike, M.G. (2007) The Changing Face of Paediatric Hydrocephalus: A Decade's Experience. Journal of Clinical Neuroscience, 14, 1049-1054. https://doi.org/10.1016/j.jocn.2006.11.004

[8] Oi, S. and Di Rocco, C. (2006) Proposal of "Evolution Theory in Cerebrospinal Fluid Dynamics" and Minor Pathway Hydrocephalus in Developing Immature Brain. Child's Nervous System, 22, 662-669. https://doi.org/10.1007/s00381-005-0020-4

[9] Preuss, M., Hoffmann, K.T., Reiss-Zimmermann, M., Hirsch, W., Merkenschlager, A., Meixensberger, J. and Dengl, M. (2013) Updated Physiology and Pathophysiology of CSF Circulation-The Pulsatile Vector Theory. Child's Nervous System, 29, 1811-1825. https://doi.org/10.1007/s00381-013-2219-0

[10] Rekate, H.L. (2011) A Consensus on the Classification of Hydrocephalus: Its Utility in the Assessment of Abnormalities of Cerebrospinal Fluid Dynamics. Child's Nervous System, 27, 1535-1541. https://doi.org/10.1007/s00381-011-1558-y

[11] Preuss, M., Kutscher, A., Wachowiak, R., Merkenschlager, A., Bernhard, M.K., Reiss-Zimmermann, M., Meixensberger, J. and Nestler, U. (2015) Adult Long-Term Outcome of Patients after Congenital Hydrocephalus Shunt Therapy. Child's Nervous System, 31, 49-56. https://doi.org/10.1007/s00381-014-2571-8

[12] Panteliadis, C.P. and Hagel, C. (2011) Hydrozephalus. In: Aksu, F., Ed., Neuropädiatrie. 4. Aufl., Uni-Med Verlag, Bremen.

[13] Chapman, T., Mahalingam, S., Ishak, G.E., Nixon, J.N., Siebert, J. and Dighe, M.K. (2015) Diagnostic Imaging of Posterior Fossa Anomalies in the Fetus and Neonate: Part 1, Normal Anatomy and Classification of Anomalies. Clinical Imaging, 39, 1-8. https://doi.org/10.1016/j.clinimag.2014.10.010

[14] Griffiths, P.D., Bradburn, M., Campbell, M.J., Cooper, C.L., Graham, R., Jarvis, D., Kilby, M.D., Mason, G., Mooney, C., Robson, S.C., Wailoo, A., MERIDIAN Collaborative Group (2016) Use of MRI in the Diagnosis of Fetal Brain Abnormalities in Utero (MERIDIAN): A Multicentre, Prospective Cohort Study. Lancet Pii, Article ID: S0140-6736(16)31723-8.

[15] Mazzola, C.A., Choudhri, A.F., Auguste, K.I., Limbrick, D.D., Jr. Rogido, M., Mitchell, L. and Flannery, A.M. (2014) Pediatric Hydrocephalus Systematic Review and Evidence-Based Guidelines Task Force. Part 2: Management of Posthemorrhagic 
Hydrocephalus in Premature Infants. Journal of Neurosurgery Pediatrics, 14 Suppl 1, 8-23. https://doi.org/10.3171/2014.7.PEDS14322

[16] Kiviniemi, V., Wang, X., Korhonen, V., Keinänen, T., Tuovinen, T., Autio, J., LeVan, P., Keilholz, S., Zang, Y.F., Hennig, J. and Nedergaard, M. (2016) Ultra-Fast Magnetic Resonance Encephalography of Physiological Brain Activity-Glymphatic Pulsation Mechanisms? Journal of Cerebral Blood Flow \& Metabolism, 36, 1033-1045. https://doi.org/10.1177/0271678X15622047

[17] Di Rocco, C., Massimi, L. and Tamburrini, G. (2006) Shunts vs. Endoscopic Third Ventriculostomy in Infants: Are There Different Types and/or Rates of Complications? A Review. Child s Nervous System, 22, 1573-1589. https://doi.org/10.1007/s00381-006-0194-4

[18] Kulkarni, A.V., Riva-Cambrin, J., Browd, S.R., Drake, J.M., Holubkov, R., Kestle, J.R., Limbrick, D.D., Rozzelle, C.J., Simon, T.D., Tamber, M.S., Wellons, J.C. 3rd, Whitehead, W.E. and Hydrocephalus Clinical Research Network (2014) Endoscopic Third Ventriculostomy and Choroid Plexus Cauterization in Infants with Hydrocephalus: A Retrospective Hydrocephalus Clinical Research Network Study. Journal of Neurosurgery Pediatrics, 14, 224-229. https://doi.org/10.3171/2014.6.PEDS13492

[19] Teo, C., Kadrian, D. and Hayhurst, C. (2013) Endoscopic Management of Complex Hydrocephalus. World Neurosurgery, 79, S21.e1-7.

[20] Reinprecht, A., Dietrich, W., Berger, A., Bavinzski, G., Weninger, M. and Czech, T. (2001) Posthemorrhagic Hydrocephalus in Preterm Infants: Long-Term Follow-Up and Shunt-Related Complications. Child s Nervous System, 17, 663-669. https://doi.org/10.1007/s00381-001-0519-2

[21] Xu, H., Wang, Z.X., Liu, F., Tan, G.W., Zhu, H.W. and Chen, D.H. (2013) Programmable Shunt Valves for the Treatment of Hydrocephalus: A Systematic Review. European Journal of Paediatric Neurology, 17, 454-461. https://doi.org/10.1016/j.ejpn.2013.04.001

[22] Kutscher, A., Nestler, U., Bernhard, M.K., Merkenschlager, A., Thome, U., Kiess, W., Schob, S., Meixensberger, J. and Preuss, M. (2015) Adult Long-Term Health-Related Quality of Life of Congenital Hydrocephalus Patients. Journal of Neurosurgery Pediatrics, 16, 621-625. https://doi.org/10.3171/2015.4.PEDS15106

[23] Vinchon, M., Rekate, H. and Kulkarni, A.V. (2012) Pediatric Hydrocephalus Outcomes: A Review. Fluids Barriers CNS, 9, 18. https://doi.org/10.1186/2045-8118-9-18

[24] Fehrenbach, M.K., Bernhard, M., Siekmeyer, M., Lippmann, N., Kiess, W., Nestler, U., Meixensberger, J. and Preuss, M. (2016) VP-Shunt Dysfunction Caused by Malaria CNS Infection. Child s Nervous System, 32, 759-760. https://doi.org/10.1007/s00381-015-2912-2

[25] Klimo, P. Jr. and Flannery, A.M. (2015) Pediatric Hydrocephalus: Systematic Literature Review and Evidence-Based Guidelines. Part 6: Preoperative Antibiotics for Shunt Surgery in Children with Hydrocephalus: A Systematic Review and Meta-Analysis. Journal of Neurosurgery Pediatrics, 16, 237-239. https://doi.org/10.3171/2014.7.PEDS14326a

[26] Klimo, P. Jr, Thompson, C.J., Baird, L.C., Flannery, A.M., Pediatric Hydrocephalus Systematic Review and Evidence-Based Guidelines Task Force (2014) Pediatric Hydrocephalus: Systematic Literature Review and Evidence-Based Guidelines. Part 7: Antibiotic-Impregnated Shunt Systems versus Conventional Shunts in Children: A Systematic Review and Meta-Analysis Journal of Neurosurgery Pediatrics, 14 
53-59. https://doi.org/10.3171/2014.7.PEDS14327

[27] Ratilal, B., Costa, J. and Sampaio, C. (2008) Antibiotic Prophylaxis for Surgical Introduction of Intracranial Ventricular Shunts: A Systematic Review. Journal of Neurosurgery Pediatrics, No. 1, 48-56. https://doi.org/10.3171/PED-08/01/048

[28] Tamber, M.S., Klimo, P. Jr, Mazzola, C.A., Flannery, A.M., Pediatric Hydrocephalus Systematic Review and Evidence-Based Guidelines Task Force (2014) Pediatric Hydrocephalus: Systematic Literature Review and Evidence-Based Guidelines. Part 8: Management of Cerebrospinal Fluid Shunt Infection. Journal of Neurosurgery Pediatrics, 14, 60-71. https://doi.org/10.3171/2014.7.PEDS14328

[29] Kennedy, C.R., Ayers, S., Campbell, M.J., Elbourne, D., Hope, P. and Johnson, A. (2001) Randomized, Controlled Trial of Acetazolamide and Furosemide in Posthemorrhagic Ventricular Dilation in Infancy: Follow-Up at 1 Year. Pediatrics, 108, 597-607. https://doi.org/10.1542/peds.108.3.597

[30] Peretta, P., Ragazzi, P., Carlino, C.F., Gaglini, P. and Cinalli, G. (2007) The Role of Ommaya Reservoir and Endoscopic Third Ventriculostomy in the Management of Post-Hemorrhagic Hydrocephalus of Prematurity. Childs Nervous System, 23, 765-771. https://doi.org/10.1007/s00381-006-0291-4

[31] Badhiwala, J.H., Hong, C.J., Nassiri, F., Hong, B.Y., Riva-Cambrin, J. and Kulkarni, A.V. (2015) Treatment of Posthemorrhagic Ventricular Dilation in Preterm Infants: A Systematic Review and Meta-Analysis of Outcomes and Complications. Journal of Neurosurgery Pediatrics, 28, 1-11. https://doi.org/10.3171/2015.3.PEDS14630

[32] Schulz, M., Bührer, C., Pohl-Schickinger, A., Haberl, H. and Thomale, U.W. (2014) Neuroendoscopic Lavage for the Treatment of Intraventricular Hemorrhage and Hydrocephalus in Neonates. Journal of Neurosurgery Pediatrics, 13, 626-635. https://doi.org/10.3171/2014.2.PEDS13397

[33] Morales, D.M., Silver, S.A., Morgan, C.D., Mercer, D., Inder, T.E., Holtzman, D.M., Wallendorf, M.J., Rao, R., McAllister, J.P. and Limbrick, D.D. Jr (2016) Lumbar Cerebrospinal Fluid Biomarkers of Posthemorrhagic Hydrocephalus of Prematurity: Amyloid Precursor Protein, Soluble Amyloid Precursor Protein $\alpha$, and L1 Cell Adhesion Molecule Neurosurgery 2016 Aug 26.

[34] Preuß, M., Thome, U., Kluge, J., Hirsch, F.W., Viehweger, A. and Nestler, U. (2015) Retroclival Arachnoid Cyst in a Preterm Infant after Ventriculitis and Intraventricular Hemorrhage-A Case Report. Child's Nervous System, 31, 347-350. https://doi.org/10.1007/s00381-014-2518-0

[35] Andresen, M. and Juhler, M. (2012) Multiloculated Hydrocephalus: A Review of Current Problems in Classification and Treatment. Childs Nervous System, 28, 357-362.

[36] Preuß, M., Preiss, S., Syrbe, S., Nestler, U., Fischer, L., Merkenschlager, A., Bertsche, A., Christiansen, H. and Bernhard, M.K. (2015) Signs and Symptoms of Pediatric Brain Tumors and Diagnostic Value of Preoperative EEG. Child s Nervous System, 31, 2051-2054. https://doi.org/10.1007/s00381-015-2842-z

[37] Januschek, E., Röhrig, A., Kunze, S., Fremerey, C., Wiebe, B. and Messing-Jünger, M. (2016) Myelomeningocele-A Single Institute Analysis of the Years 2007 to 2015. Child s Nervous System, 32, 1281-1287. https://doi.org/10.1007/s00381-016-3079-1

[38] Perez da Rosa, S., Millward, C.P., Chiappa, V., Martinez de Leon, M., Ibáñez Botella, G. and Ros López, B. (2015) Endoscopic Third Ventriculostomy in Children with Myelomeningocele: A Case Series. Pediatric Neurosurgery, 50, 113-118. https://doi.org/10.1159/000381747 
[39] Beuriat, P.A., Szathmari, A., Grassiot, B., Plaisant, F., Rousselle, C. and Mottolese, C. (2016) Role of Endoscopic Third Ventriculostomy in the Management of Myelomeningocele-Related Hydrocephalus: A Retrospective Study in a Single French Institution. World Neurosurgery, 87, 484-493.

[40] Tamburrini, G., Frassanito, P., Iakovaki, K., Pignotti, F., Rendeli, C., Murolo, D. and Di Rocco, C. (2013) Myelomeningocele: The Management of the Associated Hydrocephalus. Child s Nervous System, 29, 1569-1579. https://doi.org/10.1007/s00381-013-2179-4

[41] Graf, K., Kohl, T., Neubauer, B.A., Dey, F., Faas, D., Wanis, F.A., Reinges, M.H., Uhl, E. and Kolodziej, M.A. (2016) Percutaneous Minimally Invasive Fetoscopic Surgery for Spina Bifida Aperta. Part III: Neurosurgical Intervention in the First Postnatal Year. Ultrasound in Obstetrics \& Gynecology, 47, 158-161. https://doi.org/10.1002/uog.14937

[42] Tulipan, N., Wellons, J.C. 3rd, Thom, E.A., Gupta, N., Sutton, L.N., Burrows, P.K., Farmer, D., Walsh, W., Johnson, M.P., Rand, L., Tolivaisa, S., D’alton, M.E., Adzick, N.S. and MOMS Investigators (2015) Prenatal Surgery for Myelomeningocele and the Need for Cerebrospinal Fluid Shunt Placement. Journal of Neurosurgery Pediatrics, 16, 613-620. https://doi.org/10.3171/2015.7.PEDS15336

[43] De Ribaupierre, S., Rilliet, B., Vernet, O., Regli, L. and Villemure, J.G. (2007) Third Ventriculostomy vs. Ventriculoperitoneal Shunt in Pediatric Obstructive Hydrocephalus: Results from a Swiss Series and Literature Review. Childs Nervous System, 23, 527-533. https://doi.org/10.1007/s00381-006-0283-4

[44] Limbrick, D.D. Jr, Baird, L.C., Klimo, P. Jr, Riva-Cambrin, J., Flannery, A.M. and Pediatric Hydrocephalus Systematic Review and Evidence-Based Guidelines Task Force (2014) Pediatric Hydrocephalus: Systematic Literature Review and Evidence-Based Guidelines. Part 4: Cerebrospinal Fluid Shunt or Endoscopic Third Ventriculostomy for the Treatment of Hydrocephalus in Children. Journal of Neurosurgery Pediatrics, 14, 30-34. https://doi.org/10.3171/2014.7.PEDS14324

[45] Rasul, F.T., Marcus, H.J., Toma, A.K., Thorne, L. and Watkins, L.D. (2013) Is Endoscopic Third Ventriculostomy Superior to Shunts in Patients with Non-Communicating Hydrocephalus? A Systematic Review and Meta-Analysis of the Evidence. Acta Neurochirurgica, 155, 883-889.

https://doi.org/10.1007/s00701-013-1657-5

[46] Jernigan, S.C., Berry, J.G., Graham, D.A. and Goumnerova, L. (2014) The Comparative Effectiveness of Ventricular Shunt Placement versus Endoscopic Third Ventriculostomy for Initial Treatment of Hydrocephalus in Infants. Journal of Neurosurgery Pediatrics, 13, 295-300. https://doi.org/10.3171/2013.11.PEDS13138

[47] Kulkarni, A.V., Sgouros, S., Constantini, S. and IIHS Investigators (2016) International Infant Hydrocephalus Study: Initial Results of a Prospective, Multicenter Comparison of Endoscopic Third Ventriculostomy (ETV) and Shunt for Infant Hydrocephalus. Child's Nervous System, 32, 1039-1048. https://doi.org/10.1007/s00381-016-3095-1

[48] Holwerda, J.C., Van Braeckel, K.N., Roze, E., Hoving, E.W., Maathuis, C.G., Brouwer, O.F., Martijn, A. and Bos, A.F. (2016) Functional Outcome at School Age of Neonatal Post-Hemorrhagic Ventricular Dilatation. Early Human Development, 96, 15-20. https://doi.org/10.1016/j.earlhumdev.2016.02.005

[49] Nikas, D.C., Post, A.F., Choudhri, A.F., Mazzola, C.A., Mitchell, L., Flannery, A.M. and Pediatric Hydrocephalus Systematic Review and Evidence-Based Guidelines Task Force (2014) Pediatric Hydrocephalus: Systematic Literature Review and Evidence-Based Guidelines. Part 10: Change in Ventricle Size as a Measurement of Ef- 
fective Treatment of Hydrocephalus. Journal of Neurosurgery Pediatrics, 14, 77-81. https://doi.org/10.3171/2014.7.PEDS14330

[50] Paulsen, A.H., Lundar, T. and Lindegaard, K.F. (2010) Twenty-Year Outcome in Young Adults with Childhood Hydrocephalus: Assessment of Surgical Outcome, Work Participation, and Health-Related Quality of Life. Journal of Neurosurgery Pediatrics, 6, 527-535. https://doi.org/10.3171/2010.9.PEDS09548

[51] Paulsen, A.H., Lundar, T. and Lindegaard, K.F. (2015) Pediatric Hydrocephalus: 40-Year Outcomes in 128 Hydrocephalic Patients Treated with Shunts during Childhood. Assessment of Surgical Outcome, Work Participation, and Health-Related Quality of Life. Journal of Neurosurgery Pediatrics, 16, 633-641. https://doi.org/10.3171/2015.5.PEDS14532

[52] Oi, S., Inagaki, T., Shinoda, M., Takahashi, S., Ono, S., Date, I., Nomura, S., Miwa, T., Araki, T., Ito, S., Uchikado, H., Takemoto, O., Shirane, R., Nishimoto, H., Tashiro, Y., Matsumura, A. and COE-Fetal and Congenital Hydrocephalus Top 10 Japan Study Group (2011) Guideline for Management and Treatment of Fetal and Congenital Hydrocephalus: Center of Excellence-Fetal and Congenital Hydrocephalus Top 10 Japan Guideline 2011. Childs Nervous System, 27, 1563-1570. https://doi.org/10.1007/s00381-011-1541-7

$\begin{array}{ll}\text { Abbreviations } \\ \text { AQS } & \text { aqueductal stenosis } \\ \text { CHR } & \text { chromosome } \\ \text { CISS } & \text { constructive interference in steady state } \\ \text { CSF } & \text { cerebrospinal fluid } \\ \text { ETV } & \text { endoscopic third ventriculostomy } \\ \text { HSAS } & \text { hydrocephalus with stenosis of the aqueduct of Sylvius } \\ \text { ICP } & \text { intracranial pressure } \\ \text { IIHS } & \text { international infant hydrocephalus study } \\ \text { IVH } & \text { intraventricular hemorrhage } \\ \text { L1CAM } & \text { L1 cell adhesion molecule, CD171 } \\ \text { MKS } & \text { Meckel syndrome } \\ \text { MRI } & \text { magnetic resonance imaging } \\ \text { VAD } & \text { ventricular access device } \\ \text { VP } & \text { ventriculo - peritoneal } \\ \text { VSG } & \text { ventriculo - subgaleal }\end{array}$

